\title{
BUBBLE NUCLEATION AS A TRIGGER FOR XENOLITH ENTRAPMENT IN MANTLE MELTS
}

\author{
Nadav G Lensky ${ }^{1}$, Ron W Niebo ${ }^{2}$, John R Holloway ${ }^{2}$, Vladimir Lyakhovsky ${ }^{3}$ and Oded Navon ${ }^{1}$ \\ ${ }^{1}$ Institute of Earth sciences, The Hebrew University of Jerusalem, Jerusalem, 91904, Israel; ${ }^{2}$ Department of Geological \\ Sciences, Arizona State University, Tempe, AZ, 85827, USA; ${ }^{3}$ Geological Survey of Israel, 30 Malkhe Yisrael Street, \\ Jerusalem 95501, Israel
}

\section{INTRODUCTION}

Mantle derived xenoliths and their host alkaline magmas show evidence that they originate at depths of tens and even hundreds of kilometers in the Earth's mantle (e.g., Eggler 1989, Brey and Kohler 1990, Sautter, Haggerty and Field 1991, Ringwood 1992, Collerson, 2000). Limited reaction between xenoliths and the magma suggests short transport time. Dissolution experiments demonstrated that mantle derived garnet crystals survive in kimberlitic melt for only several hours even at near solidus temperatures (Canil 1999). Ar-Ar age data on phlogopite grains in diamond-bearing xenoliths indicate transport time of hours to days (Kelley 2000). These and other data suggest ascent rates of tens of $\mathrm{m} \mathrm{s}^{-1}$ for kimberlites to tens of $\mathrm{cm} \mathrm{s}^{-1}$ for alkali basalts (Spera 1984).

The fast ascent rates, as well as the physical size of the xenoliths indicates rapid magma ascent in dikes. This raises the problem of dike initiation and the cracking of hot, ductile rocks under mantle pressures (e.g., Rubin 1993). Another question of interest is the mechanism which leads to the trapping of xenoliths in the magma. In many cases the xenoliths do not sample randomly the full path of ascent, but rather, many of the xenoliths originate from a limited depth range. For example, why do alkali basalt carry mostly spinel peridotites, while kimberlites bring garnet peridotites?

Noting the correlation between the presence of xenoliths and the high volatile content of the carrying magma, we examine the possible role of volatiles in the trapping of xenoliths by ascending magmas and in the initiation of dikes. Based on new experimental data on the nucleation of $\mathrm{CO}_{2}$ bubbles in alkaline basaltic magma and a bubble growth model, we suggest that explosive growth of gas bubbles may lead to cracking of the wall rock and trapping of xenoliths. We also discuss the possible role of bubble nucleation and growth as a trigger for transition from channel flow to dikes.

\section{THE ROLE OF VOLATILES IN THE FAST ASCENT OF ALKALINE MAGMA}

The transport of xenolith-bearing magmas across the lithosphere at high ascent rates requires magma flow in a fracture as opposed to diapiric mechanism, which is much slower (Spera 1984, Spence 1990, Rubin 1993). Solving the appropriate set of conservation equations, Spera (1984) found that volatile exsolution in magmas cannot explain the high flow velocities in terms of viscous flow. However volatiles play a major role in the dynamics of crack propagation and in the fast ascent of magmas. Spera reported that the most sensitive parameters governing ascent rate are the initial magma flux and the local magma pressure, which are all functions of volatile content.

Spence and Turcotte (1990) calculated the ascent rate and flow regime of magma-filled crack driven by differential buoyancy and found that bubbly kimberlites (low density) flow fast enough to transport diamond bearing xenoliths to the surface and that the flow is turbulent. The low magma density is explained by significant $\mathrm{CO}_{2}$ degassing (Girnis 1995). Rubin (1998) derived time dependent analytical solutions for the growth of buoyant dikes fed by porous flow in partly molten rocks, in the source regions of magmas. Melt is driven into the dike by the difference between the ambient pore pressure and the least compressible stress, and driven up the dike by magma buoyancy. Because channel flow is very efficient relative to porous flow, the model predicts thin dikes, a few kilometer long dike may be only a few millimeter in thickness. Lister et al. (1991) considered magma transport through dyke in an elastic, deformable medium and calculated the effect of cooling and solidification of the dike. They found that komateiites erupt in preference to basalts because they are less prone to freezing and their viscosity is lower. The problem of dike initiation is still not yet solved and the situation remained as described by Rubin (1993): "any discussion of dike propagation in a partial melt begs the question of crack initiation, but is not near at hand". The extremely high strength expected at the depth of xenolith collection precludes crack formation by shear. Rubin (1998) suggested that the process of magma generation and accumulation in pores between 
grains is driven by pore pressure and initiation of grainscale cracks. Nevertheless, fast formation of major cracks needed for fast xenolith transport is not explained.

Girnis et al. (1995) suggested that kimberlitic eruptions are triggered by saturation of $\mathrm{CO}_{2}$ and degassing at around $6 \mathrm{GPa}$ and subsequent extensive degassing at 6$4 \mathrm{GPa}$. Based on nucleation experiments, we suggest here that if such melts reach critical supersaturation for bubble nucleation, high enough pressures may develop and a lead to crack formation, trapping of xenoliths and dike initiation.

\section{NUCLEATION OF GAS BUBBLES AT DEPTH}

As magma ascends and decompresses it becomes supersaturated with volatiles. In the case of alkaline magmas the main volatile species is $\mathrm{CO}_{2}$. If ascent is fast enough so that the excess volatiles cannot diffuse through the magma body, supersaturation increases until it reaches a critical level and bubbles nucleate. The critical nucleus is in chemical and mechanical equilibrium. The gas pressure is higher than the ambient pressure as it is in chemical equilibrium with the supersaturated melt. The pressure difference on the interface is compensated by the surface tension and the net force on the bubble-melt interface is zero.

$P_{\text {gas }}=P_{\text {sat }}=P_{\text {amb }}+P_{\text {surf }}$

The surface tension pressure depends on bubble radius and so the critical nucleus is:

$$
R_{c r i t}=\frac{2 \sigma}{P_{g a s, 0}-P_{a m b, 0}}=\frac{2 \sigma}{\Delta P}
$$

where $\Delta \mathrm{P}$ is the critical supersaturation pressure, and subscript 0 refers to $\mathrm{t}=0$. The nucleation rate depends strongly on $\sigma$ and $\Delta \mathrm{P}$ and once critical supersaturation is achieved nucleation is instantaneous (Navon and Lyakhovsky 1998).

\section{NUCLEATION EXPERIMENTS}

We measured the supersaturation needed for nucleation of $\mathrm{CO}_{2}$ bubbles in basanitic melt. $\mathrm{A} \mathrm{CO}_{2}$-rich synthetic basanite (similar to Peridot Mesa Basanite) was prepared from laboratory grade oxides (including ferrous and ferric iron) and carbonates. $\mathrm{CO}_{2}$ was introduced in excess as $\mathrm{Na}_{2} \mathrm{CO}_{3}$. After drying, the mixture was loaded in platinum capsules, packed in the pressure assembly and run in a piston-cylinder at 1.5 $\mathrm{GPa}, 1350^{\circ} \mathrm{C}$ for $4-5$ hours. $\mathrm{CO}_{2}$ solubility at $1.5 \mathrm{GPa}$, $1350^{\circ} \mathrm{C}$ was measured using SIMS and FTIR and is $1.4 \pm 0.2 \mathrm{wt} \%$. Water was also present at levels of $\sim 0.7$ wt $\%$. After saturation, pressure was lowered at decompression rate of $\sim 10 \mathrm{MPa} / \mathrm{s}$ and held constant at the final pressure for 5-20 minutes. The experiments were then quenched isobarically at $\sim 300^{\circ} \mathrm{C} / \mathrm{s}$, samples were liberated, sectioned, polished and examined microscopically for their bubble number density and size distribution and for their volatile content.

The results are presented in Fig. 1. No nucleation was observed after decompressing the sample by $0.1 \mathrm{GPa}$ (four runs held for 5-40 minutes at $1.4 \mathrm{GPa}$ ). Decompression yielded bubbles in a run held at $1.3 \mathrm{GPa}$ for 20 minutes, and at $1.2 \mathrm{GPa}$ for 10 and 20 minutes, but not after 5 minutes at $1.2 \mathrm{GPa}$. We conclude that supersaturation of $0.1-0.2 \mathrm{GPa}$ is the minimum needed for nucleation of $\mathrm{CO}_{2}$ bubbles in alkaline basaltic melts.

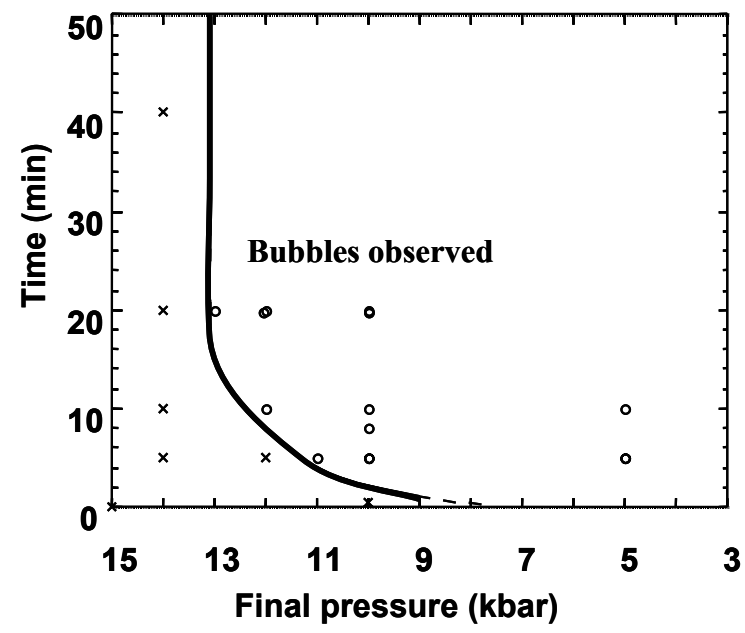

Fig. 1. Summary of nucleation experiments. Open symbols no bubbles were observed after quenching. Solid symbols bubbles were present at the end of the run.

\section{MODEL: INCREASE OF GAS PRESSURE FOLLOWING NUCLEATION}

We consider a batch of bubbly magma enclosed in an infinite elastic medium (Fig. 2). The magma is decompressed, reaches critical supersaturation and nucleates bubbles at $\mathrm{t}=0$. If the initial nucleus is bigger than critical, $P_{\text {surf }}=2 \sigma / R_{0}<2 \sigma / R_{\text {crit }}$ and $P_{\text {gas }}>P_{\text {amb }}+P_{\text {surf }}$, bubbles expand, magma volume grows, the walls deform and, consequently, ambient pressure increases. The equation of motion of the viscous melt has the following form:

$$
P_{\text {gas }}-P_{\text {amb }}=2 \frac{\sigma}{R}+4 \eta_{\text {eff }} \frac{\dot{R}}{R}
$$

where the effective viscosity $\eta_{\text {eff }}=\eta(1-\varepsilon)$ accounts for the gas volume fraction $\varepsilon$, and the dot sign denotes for 
time derivative. Radial viscosity variations are negligible since, due to the efficient diffusion and the fast rise of $P_{a m b}, P_{\text {gas }}$ remains close to the supersaturation pressure during the whole process.
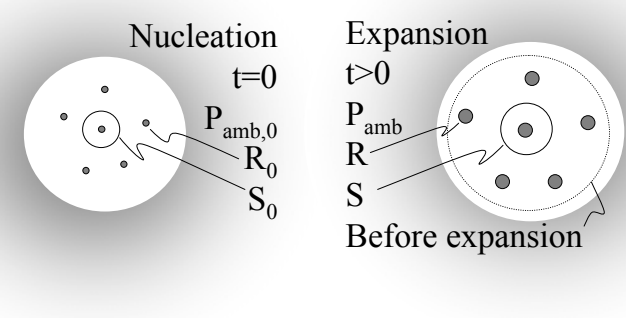

Fig. 2. The system consists of bubble bearing magma enclosed in an elastic medium.

Assuming $P_{\text {gas }}=$ const and substituting (2) into (3) yields:

$$
4 \eta_{\text {eff }} \frac{\dot{R}}{R}=P_{g a s}-P_{a m b}-\left(P_{g a s}-P_{a m b, 0}\right) \frac{R_{0}}{R}
$$

The response of the surrounding elastic medium to gas expansion is:

$$
P_{a m b}-P_{a m b, 0}=\frac{4}{3} G \frac{R^{3}-R_{0}^{3}}{S_{0}^{3}}=\frac{4}{3} G \varepsilon_{0}\left(\frac{R^{3}}{R_{0}^{3}}-1\right)
$$

where $G$ is shear modulus. Substituting (4) into (3) yields:

$$
\begin{aligned}
& 4 \eta_{e f f} \frac{\dot{R}}{R}= \\
& \left(1-\frac{R_{0}}{R}\right)\left(\left(P_{a m b}-P_{a m b, 0}\right)-\frac{4}{3} G \varepsilon_{0} \frac{R}{R_{0}}\left(\frac{R^{2}}{R_{0}^{2}}+\frac{R}{R_{0}}+1\right)\right)
\end{aligned}
$$

It is useful to transform the equations to a nondimensional form:

$$
\dot{\bar{R}}=\frac{\bar{R}-1}{1-\alpha}\left(1-\frac{4 G \varepsilon_{0}}{3 \Delta P} \bar{R}\left(\bar{R}^{2}+\bar{R}+1\right)\right)
$$

where the pressure scale is $\Delta P=P_{g a s}-P_{a m b, 0}$, the viscosity scale $\eta$, and the length scale is $R_{0}$. The dimensionless elastic response, $4 G \varepsilon_{o} / 3 \Delta P$, is a governing parameter of the process.
The minimal condition for initial growth of the nucleus is obtained by solving equation (6) ensuring that $\dot{R}>0$ while $R \sim R_{0}$ :

$$
\Delta P / \varepsilon_{0} G>4 \text {. }
$$

If this condition is satisfied, then the bubbles grow and ambient pressure increases.

Initially, diffusion is very efficient and bubble growth is controlled by viscous deformation (Navon and Lyakhovsky 1998):

$\tau_{v i s}=4 \eta / \Delta P$.

$\Delta \mathrm{P}$ was determined in the experiments and is of the order of $10^{8} \mathrm{~Pa}$. Using the low viscosities of kimberlites or alkali basalts, about $1 \mathrm{~Pa} \mathrm{~s}$, the time scale for growth is $10^{-8} \mathrm{~s}$.

The viscous time scale is longer than the Maxwell time scale:

$\tau_{\text {vis }}=\eta / G$,

since $G$ is of the order of $10^{10} \mathrm{~Pa}$. Thus, it is clear that elasticity in the melt is unimportant for bubble growth, and deformation is by a viscous mechanism. The pressure and volume change due to expansion takes micro-seconds, according to solution of equations (5) and (6) and assuming fast diffusion.

The diffusive time scale, $\mathrm{R}^{2} / \mathrm{D}$ is longer, but still with $\mathrm{D}_{\mathrm{CO} 2}$ of $10^{-10}$, diffusive growth also occurs on a time scale of less than a second for bubbles of up to $10 \mu \mathrm{m}$. In the surrounding mantle rocks, viscosity is much higher, $\eta>10^{15} \mathrm{~Pa} s$ (McKenzie 1984), thus Maxwell time for the wall rocks is longer than all other timescales by more than four orders of magnitude and the response of the wall-rock is expected to be elastic.

The maximum pressure difference that is induced by expansion of bubbles is obtained from the conditions for volatile mass conservation under the final pressure exerted by the walls:

$$
R_{f}^{3} \rho_{\text {gas }, \mathrm{f}}=S^{3}{ }_{0}\left(C\left(P_{\text {sat }}\right)-C\left(P_{\text {gas }, f}\right)\right)
$$

At this static situation equation (3) reduces to

$P_{\text {gas }, f^{-}} P_{a m b, f}=2 \sigma / R_{f}$

Substitution of (11) and (12) into (5) yields:

$$
P_{g a s, f}-2 \frac{\sigma}{R_{f}}-P_{a m b, 0}=\frac{4}{3} G\left(C\left(P_{s a t}\right)-C\left(P_{g a s, f}\right)\right) \frac{\rho_{\text {melt }}}{\rho_{g a s, f}}
$$

$R_{f}$ can be substituted by (11), but commonly it is large enough so that the surface tension term may be neglected. Using the appropriate solubility law and the $\mathrm{CO}_{2}$ equation of state, equations (12) and (13) may be solved for the final gas pressure and the final pressure exerted on the wall, which are equal for large enough bubbles. 
Fig. 3 presents $P_{a m b, f}$ as a function of $\partial \mathrm{C} / \partial \mathrm{P}$. Initial supersaturation of 1-2 kbar would lead to final compression of the walls by $0.2-1.0 \mathrm{kbar}$ depending on the solubility law, but also on our choice of $G$ and $P_{a m b, 0}$. The cases of kimberlite and alkali basalts are discussed below.

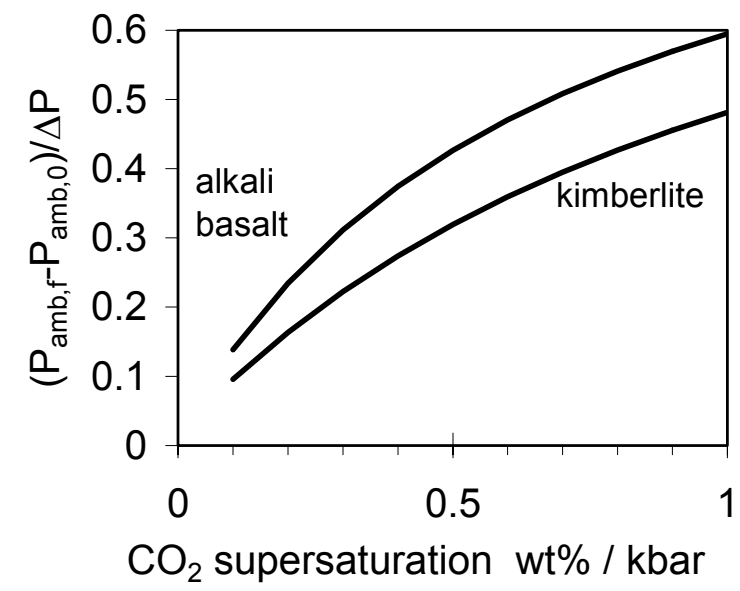

Fig. 3. Final ambient pressure following nucleation and bubble expansion. Pressure is normalized to the supersaturation pressure $(\Delta \mathrm{P})$. The solubility law is assumed to be linear for this small pressure interval and the $\mathrm{x}$-axis units are in $\mathrm{wt} \% \mathrm{CO}_{2}$ per $1 \mathrm{kbar}(0.1 \mathrm{GPa})$ decompression. In the solution we used $\mathrm{CO}_{2}$ density data of Frost and Wood (1997), $\mathrm{G}=10 \mathrm{GPa}, \rho_{\text {melt }}=2800 \mathrm{~kg} / \mathrm{m}^{3}, \Delta \mathrm{P}=0.15 \mathrm{GPa}, \mathrm{P}_{\mathrm{amb}, 0}=1.35 \mathrm{GPa}$ (upper line) and $5 \mathrm{GPa}$ (lower line).

\section{DISCUSSION}

The experimental data presented here indicates that supersaturation pressure of 0.1-0.2 GPa are needed for the nucleation of $\mathrm{CO}_{2}$ bubbles in basanitic melts. This value are in the range of supersaturation pressure recorded for the nucleation of water and $\mathrm{CO}_{2}$ bubbles in rhyolitic melts (Mangan 2000, Murtada-Bonepoi 2002). Hurwitz and Navon (1994) pointed out the importance of heterogeneous nucleation that may lead to bubble nucleation at lower supersaturation, leading to lower compression of the wall-rock. The experiments we conducted were run above the liquidus and we know of no data on heterogeneous nucleation of $\mathrm{CO}_{2}$ bubbles. Another difficulty that must be considered is the possibility that during slow decompression (e.g. during diapiric ascent prior to the initiation of a dike), the supersaturated melt may lose $\mathrm{CO}_{2}$ by reacting with wall-rock silicates in carbonation reactions, and avoid nucleation. In the following we assume homogeneous nucleation at supersaturation pressure of 0.1-0.2 GPa.
Supersaturation may develop in $\mathrm{CO}_{2}$-bearing magma due to decrease of ambient pressure during ascent of magma in a diapir or a dike, or due to crystallization. When critical supersaturation is reached bubbles nucleate and expand. Our calculations show that bubble growth following nucleation is very fast. After much less than a second, bubbles are fully grown and due to the elastic response of the wall rock and consequently ambient pressure is elevated. If pressurization is large enough the rock is damaged and cracks may develop.

As shown by equation (13) the factors controlling the pressurization are the bulk modulus, the solubility law, the ambient pressure and the critical supersaturation pressure.

We examine the case of basanitic melt containing 1.4 $\mathrm{wt} \% \mathrm{CO}_{2}$ that reaches critical supersaturation at 1.3-1.4 $\mathrm{GPa}$ after decompression from equilibrium at $1.5 \mathrm{GPa}$ and $1350^{\circ} \mathrm{C}$. The slope of the solubility curve (Holloway and Blank, 1994) corresponds to $1 \mathrm{wt} \% \mathrm{CO}_{2}$ per $\mathrm{GPa}$. Using the bulk modulus and $\mathrm{CO}_{2}$ density data (Fig. 3) and $\mathrm{P}_{\mathrm{amb}, 0}$ of $1.35 \mathrm{GPa}$, the solution of equation (13), shown in Fig. 3, predicts that for supersaturation of $0.15 \mathrm{GPa}$, pressurization may reach 20-40 MPa. Such loading is high enough to initiate cracks and trap xenoliths.

This mechanism suggests a discrete event of xenolith trapping. Following this "explosion" the ascending magma may add occasional nodules due to bifurcation of the dike leading crack, but most of the xenoliths originate at the depth of the nucleation event. This may explain why many alkali basalts carry mostly spinel peridotites. The trace element patterns of such basalts clearly indicate equilibration with garnet peridotites at deeper depth. However, garnet peridotite xenoliths as well as crustal nodules are not represented in the xenolith assemblage. We suggest that this situation is a result of nucleation of $\mathrm{CO}_{2}$ bubbles at the spinel peridotite zone. Other basalts, sometime in a nearby location are loaded with crustal nodules, but carry no spinel, or garnet peridotites. This may reflect lower initial concentration of $\mathrm{CO}_{2}$, and achievement of critical supersaturation at lower crustal depth.

In the case of an ascending kimberlite, the slope of the solubility curve is steeper and may reach $10 \mathrm{wt} \% \mathrm{CO}_{2}$ per GPa (Brey et al. 1991). At $\mathrm{P}_{\mathrm{amb}, 0}$ of $5 \mathrm{GPa}$ similar critical supersaturation of $0.1-0.2 \mathrm{GPa}$ will result in even higher loading of 0.06-0.13 GPa (600-1300 bar). Such an event may also develop according to a scenario suggested by Girnis et al. (1995). They suggested that when a kimberlite ascending from deep in the mantle 
reaches the lithosphere partial crystallization due to reaction with the lithospheric rocks may elevate $\mathrm{CO}_{2}$ concentrations to critical supersaturation. Once this critical level is reached, the process should continue according to the scenario developed above.

As a dike is initiates, subsequent growth of bubbles should play a key role in the propagation of the tip of the dike and in maintaining sufficient overpressure to drive the magma up the lithosphere.

Research was funded by the Israel-US Binational Science Foundation and EC MULTIMO project. NGL acknowledges support by Yeshaya Hurwitz Fellowship.

\section{REFERENCES}

Brey, G.P. and Kohler, T., 1990. Geothermometry in fourphase lherzolites II. New thermobarometers, and practical assessment of existing thermobarometers. J. Petrol. 31, 1353-1378.

Brey, G.P., Kogarko, L.N. and Ryabchikov, I.D., 1991. Carbon dioxide in kimberlitic melts. Neues Jahrb. Mineral. Monatsh. 4, 159-168.

Canil, D. and Fedortchouk, Y., 1999. Garnet dissolution and the emplacement of kimberlites. Earth and Planet. Sci. Lett. 167, 227-237.

Collerson, K.D., Hapugoda, S., Kamber, B.S. and Williams, Q., 2000. Rock from the Mantle Transition Zone: Majorite-bearing xenoliths from Malaita, Southern Pacific. Science 288, 12151223.

Eggler, D.H., 1989. Kimberlites: how do they form? In: Ross, J., et al. (Eds.), Kimberlites and related rocks. Blackwell, Melbourne, pp. 489-504.

Frost, D.J. and Wood, B.J., 1997. Experimental measurements of the properties of $\mathrm{H} 2 \mathrm{O}-\mathrm{CO} 2$ mixtures at high pressures and temperatures. Geochim. et Cosmochim. acta 61, 3301-3309.

Girnis, A.V., Brey, G.P. and I.D. Ryabchikov, 1995. Origin of Group 1A kimberlites: Fluid-saturated melting experiments at 45-55 kbar. Earth and Planet. Sci. Lett. 134, 283-296.

Holloway, J.R., Blank, J.G., 1994. Application of experimental results to $\mathrm{C}-\mathrm{O}-\mathrm{H}$ species in natural melts, Rev. in Mineral. 30, 187-230.

Hurwitz, S. and Navon, O., 1994. Bubble nucleation in rhyolitic melts: experiments at high pressure, temperature and water content. Earth and Planet. Sci. Lett. 122, 267-280.

Kelley, S.P. and Wartho, J.-A., 2000. Rapid kimberlite ascent and the significance of $\mathrm{Ar}-\mathrm{Ar}$ ages in xenolith phlogopites. Science 289, 609-611.

Lister, J.R., Campbell, I.H. and Kerr R.C., 1991. The eruption of komatiites and picrites in preference to primitive basalts. Earth and Planet Sci. Lett. 105, 343-352.

Mangan, M. and Sisson, T., 2000. Delayed disequilibrium degassing in rhyolite magma: decompression experiments and implications for explosive volcanism. Earth and Planet. Sci. Lett. 183, 441455.

McKenzie, D., 1984. The extraction of magma from the crust and mantle. Earth and Planet. Sci. Lett. 74, 81-91.

Mourtada-Bonnefoi, C.C. and Laporte, D. 2002. Homogeneous bubble nucleation in rhyolitic magmas: an experimental study of the effect of $\mathrm{H} 2 \mathrm{O}$ and CO2. J. Geophys. Res. Sol. Earth 107 art. no. 2066

Navon, O. and Lyakhovsky, V., 1998. Vesiculation processes in silicic magmas. In: Gilbert, J.S. and Sparks, R.S.J. (Eds.), The physics of explosive eruptions. Geological Soc., London, Special Publications 145, 27-50.

Ringwood, A.E., Kesson, S.E., Hibberson, W. and Ware, N., 1992. Origin of kimberlites and related magmas. Earth and Planet. Sci. Lett. 113, 521-538.

Rubin, A.M., 1993. Dikes vs. diapirs in viscoelastic rock. Earth and Planet. Sci. Lett. 119, 641-659.

Rubin, A.M., 1998. Dike ascent in partially molten rock. J. Geophys. Res. 103, 20,901-20,919.

Sautter, V., Haggerty, S.E. and Field, S., 1991. Ultra deep $(>300 \mathrm{~km})$ ultramafic xenolites: new petrologic evidence from the transition zone. Science 252 , 827-830.

Spence, D.A. and Turcotte, D.L., 1990. Bouyancy-driven magma fracture; a mechanism for ascent through the lithosphere and the emplacement of diamonds. J. Geophys. Res. 95, 5133-5139.

Spera, F.J., 1984. Carbon dioxide in petrogenesis III: role of volatiles in the ascent of alkaline magma with special reference to xenolith-bearing mafic laves. Contrib. Mineral. Petrol. 88, 217-232.

Turcotte, D.L., 1990. On the role of laminar and turbulent flow in buoyancy driven magma fractures. In: Ryan, M.P. (Ed.), Magma transport and storage. John Whiley and Sons Ltd.

Contact: O Navon, Institute of Earth sciences, The Hebrew University of Jerusalem, Jerusalem, 91904, Israel, E-mail: oded.navon@huji.ac.il 